\title{
EFFECTIVE PARAMETERS OF TAIL PROCESSING GOLD-BEARING ORE HYDROTRANSPORT FOR VERNINSKAYA PROCESSING FACTORY
}

\author{
Victor I. ALEXANDROV ${ }^{1 *}$, Pavel N. MAHARATKIN ${ }^{2}$, Inna S. TRUFANOVA ${ }^{3}$ \\ ${ }^{1}$ Mining Transport Machines Department, Saint-Petersburg Mining University, Russia; victalex@mail.ru, \\ ORCID: 0000-0003-2459-4168 \\ ${ }^{2}$ Mining Transport Machines Department; Saint-Petersburg Mining University, Russia; pavelnik@spmi.ru, \\ ORCID: 0000-0002-9376-061X \\ ${ }^{3}$ Mining Transport Machines Department; Saint-Petersburg Mining University, Russia; trinna@spmi.ru, \\ ORCID: 0000-0003-3182-9746 \\ * Correspondence author
}

Purpose: The paper shows that in order to increase the efficiency of hydraulic transport systems in mining a transition to the transportation of slurries with a high concentration of solids in the slurry flow is necessary.

Design/methodology/approach: The aim of the research is to determine the optimal concentrations to ensure effectiveness of thickened tailings hydrotransport using the example of the Verninskaya processing factory, taking into account the maximum possible concentration of the solid phase and the rheological properties of the pulp.

Findings: Experimental studies have shown that slurry tailings of gold-containing ore with mass concentrations of more than $55 \%$ are viscoplastic fluids. Experiments on a rotational viscometer allowed us to establish the main rheological characteristics of the studied slurries - shear stress and the dynamic effective viscosity. It has been established that over the entire range of concentrations from 55 to $65 \%$, the flow of slurries is described by the Bingham rheological equation. Experimental studies of hydraulic transport performed on a laboratory setup with a pipeline diameter of $50 \mathrm{~mm}$ confirmed the results obtained on a rotational viscometer. Curves of mixture stream are inclined straight lines that cut off on the axis of head of the sections, which determine the initial hydraulic slope corresponding to the yield shear stress on the rheological curves.

Originality/value: According to the results of the experiments, a method has been developed for calculating the hydraulic transport of high concentrated slurries of tailings of gold-bearing ore. Calculations showed that in a given range of performance of hydrotransport system and the mass concentration of the solid phase pressure losses vary from 11 to $84 \mathrm{~m}$ water column $/ \mathrm{m}$. Head loss values grow with increasing concentration. A sharp increase in head loss occurs in the concentration range from 60 to $65 \%$ and above.

Keywords: hydrotransport, solid particles, concentration, shear stress, viscosity, head losses.

Category of the paper: research paper. 


\section{Introduction}

Hydrotransport systems at mining and processing plants of Russia are designed and built mainly in the $60 \mathrm{~s}$ of the last century and currently do not meet modern requirements for technical and economic efficiency and energy intensity of the ore processing tailings transportation. The main reasons for this condition of mining and processing plants' hydrotransport systems are low concentration of solids in the transported pulp flow; large volumetric flows that require the use of high-capacity pumps; high metal intensity for hydrotransport systems due to large pipe diameters; significant energy costs for the return of recycled water to the processing. To improve the efficiency of hydrotransport systems, a complete modernization of the technological process of pumping tailings and the development of new design solutions is necessary. Such projects of hydraulic transport systems reconstruction at mining and processing plants are carried out by the hydro-technical department of CJSC "Mekhanobr Engineering". The main idea of projects for the reconstruction of hydrotransport systems is the transition to the transportation of thickened tailings. The theoretical and experimental substantiation of design solutions is carried out by the Mining Transport Machines Department of Saint-Petersburg Mining University.

When designing hydrotransport systems for various slurries with high concentrations of solid, and in some cases to the paste state, it is necessary to consider:

- mechanical properties of pulp,

- features of rheological characteristics,

- high pulp density and viscosity,

- a significant reduction in volume flow of the slurry,

- increase in specific head loss.

The possibilities for thickening tailings slurries to high concentrations (more than $30 \%$ by the mixture volume) depend primarily on the mineral composition of the ore being processed, the residual mineral composition of the tailings and the solid particles size distribution. In this case, we can assume that the flow structure is homogeneous, and the slurry is resistant to delamination, i.e. for a long time there is no visible separation of the pulp into liquid and solid phases. At high concentrations, the slurry of fine tailings becomes like pastes. The aim of the research is to determine the optimal concentrations to ensure effectiveness of thickened tailings hydrotransport using the example of the Verninskaya processing factory, taking into account the maximum possible concentration of the solid phase and the rheological properties of the pulp. 


\section{Initial data and preliminary calculations}

Grain size distribution. The granulometric composition of gold-bearing ore tailings from the Verninskoye deposit is represented by small particle size classes (Table 1). The integral curve of the particle size distribution is shown in Figure 1.

\section{Table 1.}

Grain size distribution of the processing tailings of gold-bearing ore from the Verninskoye deposit

\begin{tabular}{|c|c|}
\hline Size class $\left(\mathrm{d}_{\mathrm{i}}, \mathrm{mm}\right)$ & Content $\left(\mathrm{P}_{\mathrm{i}}, \%\right)$ \\
\hline$-0.15+0.1$ & 15.74 \\
\hline$-0.1+0.071$ & 10.80 \\
\hline$-0.071+0.045$ & 14.76 \\
\hline$-0.045+0.00$ & 58.70 \\
\hline$d_{0}=\frac{\sum P_{i} d_{i}}{10}=0.051 \mathrm{~mm}$ & $\sum P_{i}=100 \%$ \\
\hline
\end{tabular}

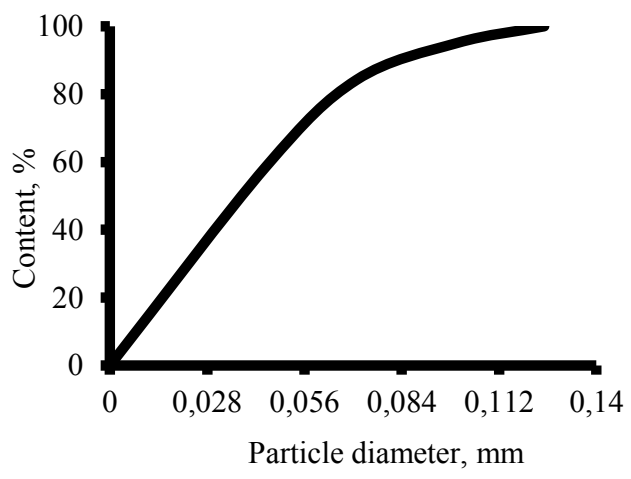

Figure 1. Integral granularity curve.

Taking into account the hydrophobicity of solid particles, they are well wetted with water and a shell is formed on the surface of the particles, and the particle itself turns into a dipole. Many small solid particles-dipoles in the considered volume of the slurry form a spatial structure (skeleton), at certain points of which there may be solid particles of larger fractions that do not have a significant effect on the overall structure, since the number of such particles is much smaller than the number of small particles - dipoles. Slurry of such solid particles does not separate into liquid and solid phase for a long time; such slurries are homogeneous or stable. Sedimentation stability depends on the volumetric content of particles in the slurry. With an increase in the amount of solid phase (volume concentration), the stability of the slurry increases.

Density of solid material. The density of the solid material is $2700 \mathrm{~kg} / \mathrm{m}^{3}$. The density of solid particles and their concentration determine the density of the slurry in accordance with the formula:

$$
\rho_{h}=c_{v}\left(\rho_{s}-\rho_{0}\right)+\rho_{0}
$$


where:

$c_{v}$ - volume concentration,

$\rho_{s}$ - density of solid,

$\rho_{0}-$ density of water.

The volume concentration can be expressed through water content in the slurry in accordance with the formula:

$$
c_{v}=\left(\rho_{s} L+1\right)^{-1}
$$

where: $L-$ mass content of water in slurry.

Mass concentration of the slurry is calculated from the ratio $S: L$ :

$$
c_{p} \frac{S}{S+L}
$$

where: $S$ - mass content of solid in slurry.

Productivity of solid tailings. The specified performance of tailings enrichment is:

- $\quad$ average $-Q_{m . s}=270 \mathrm{t} / \mathrm{h}$;

- maximum $-Q_{\max . s}=290 \mathrm{t} / \mathrm{h}$.

Productivity in combination with the solid material density and its concentration in the slurry stream determines the flow rate of the hydrotransport system, in accordance with the formula:

$$
Q_{h}=\frac{Q_{s}}{\rho_{s} c_{v}}=Q_{v}\left(L+\frac{1}{\rho_{s}}\right), \mathrm{m}^{3} / \mathrm{h}
$$

From the formula, it follows that the volume flow of the slurry decreases with an increase in concentration or with a decrease in the proportion of water. Figure 2 shows a graph of the change in volumetric flow with a change in mass concentration $c_{p}$.

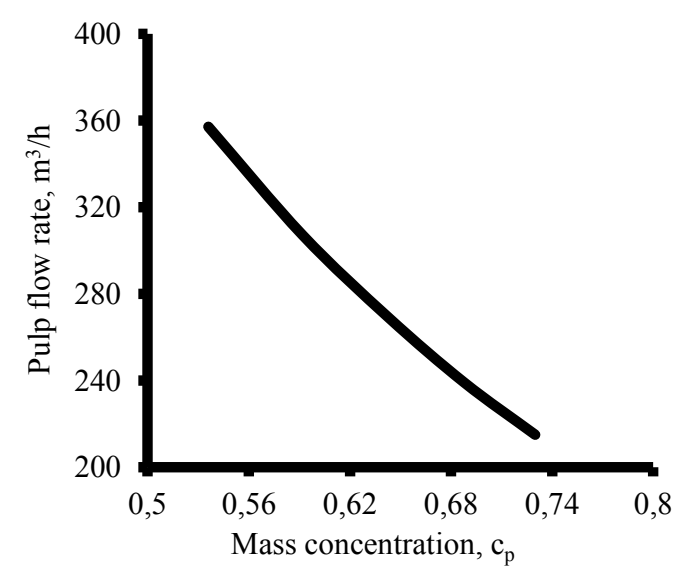

Figure 2. Pulp flow rate based on concentration of solid material.

Preliminary calculations. For a preliminary assessment of the specific energy loss during hydraulic transportation of highly concentrated slurries of gold-bearing ore tailings, a calculation method developed for viscoplastic mixtures was used (Paterson, 2004). A feature of the calculation method is the dependence of the parameters on the value of the Reynolds 
number. It is assumed that the pulp flow regime occurs in the region of hydraulically smooth pipes with the $R e=3500-5000$. The viscosity of the slurry increases with increasing concentration and the flow regime approaches laminar. The calculated values are given in Table 2, where: $c_{p}$ - the value of mass concentration, $c_{v}$ - the value of volume concentration; $S: L$ - ratio; $\rho_{h}$ - slurry density; $Q_{h}$ - volume flow of slurry; $D_{\text {pipe }}$ - the calculated internal diameter of the pipe; $v_{m}$-average flow rate of slurry in the pipe, $\mathrm{m} / \mathrm{s} ; i_{h}-$ head loss (hydraulic slope), $\mathrm{m} / \mathrm{km}$.

Table 2.

Estimated results of hydrotransport thickened tails in Verninskaya gold extraction plant

\begin{tabular}{|c|c|c|c|c|c|c|c|c|}
\hline № & $c_{p}, \%$ & $c_{v}, \%$ & $\rho_{h}, \mathrm{~kg} / \mathrm{m}^{3}$ & $Q_{h}, \mathbf{m}^{3} / \mathbf{h}$ & $D_{\text {pipe }}, \mathbf{m}$ & $v_{h}, \mathbf{m} / \mathbf{s}$ & $i_{h}, \mathbf{m} / \mathbf{k m}$ & $\frac{S}{L}$ \\
\hline \multicolumn{9}{|c|}{ Reynolds number $\operatorname{Re}=\mathbf{3 5 0 0}$} \\
\hline 1 & 0.536 & 0.3 & 1510 & 357.8 & 2.729 & 0.017 & 2.0 & $1 / 0.864$ \\
\hline 2 & 0.592 & 0.35 & 1592 & 306.8 & 1.504 & 0.048 & 4.0 & $1 / 0.687$ \\
\hline 3 & 0.648 & 0.4 & 1680 & 269.1 & 0.843 & 0.134 & 10 & $1 / 0.555$ \\
\hline 4 & 0.688 & 0.45 & 1765 & 238.6 & 0.479 & 0.368 & 21 & $1 / 0.453$ \\
\hline 5 & 0.73 & 0.5 & 1850 & 214.6 & 0.275 & 1.004 & 52 & $1 / 0.37$ \\
\hline \multicolumn{9}{|c|}{ Reynolds number $R e=4000$} \\
\hline 6 & 0.592 & 0.35 & 1592 & 308.3 & 1.316 & 0.063 & 5 & $1 / 0.687$ \\
\hline \multicolumn{9}{|c|}{ Reynolds number $\boldsymbol{R e}=\mathbf{5 0 0 0}$} \\
\hline 14 & 0.592 & 0.35 & 1592 & 360 & 1.91 & 0.098 & 6 & $1 / 0.687$ \\
\hline 15 & 0.643 & 0.4 & 1680 & 306 & 1.051 & 0.273 & 14 & $1 / 0.555$ \\
\hline 16 & 0.688 & 0.45 & 1765 & 268.5 & 0.59 & 0.750 & 33 & $1 / 0.453$ \\
\hline 17 & 0.73 & 0.5 & 1850 & 237.8 & 0.335 & 2.048 & 97 & $1 / 0.37$ \\
\hline
\end{tabular}

Figure 3 shows the graphical dependences of changes in the basic parameters of hydrotransport for the concentration of solid material in the range from $53.6 \%$ to $73 \%$ by weight, which corresponds to the ratio $S: L=\frac{1}{0.864} \div \frac{1}{0.37}$ and (30-50)\% volume concentration. The specific pressure loss varies from 5 to $64 \mathrm{~m} / \mathrm{km}$.

a)

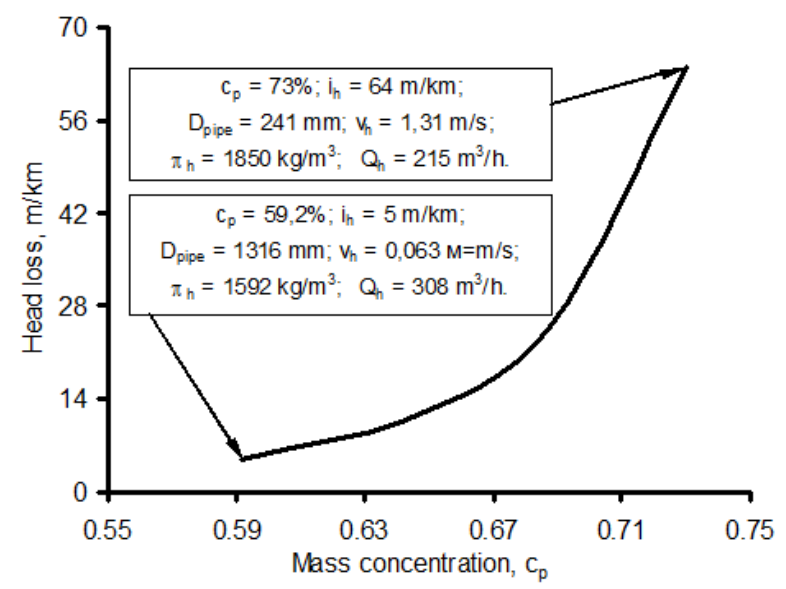

b)

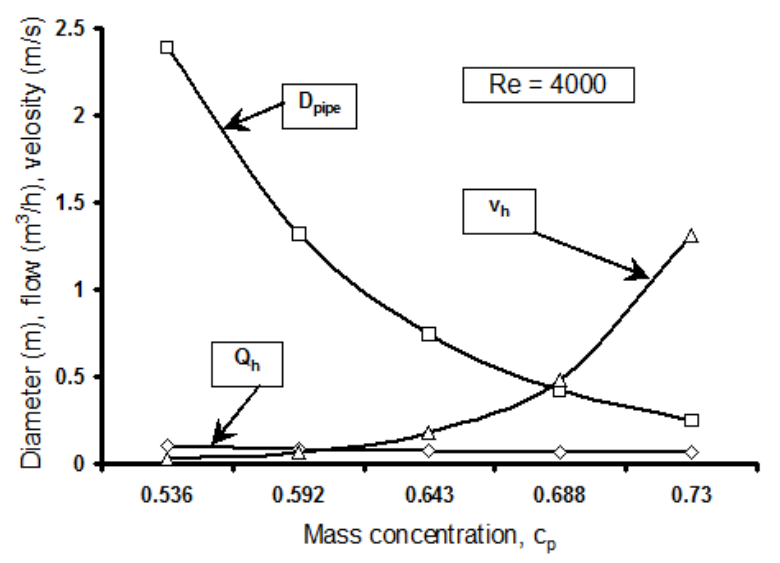

Figure 3. Head loss (a), pipe diameter, flow rate of the mixture and average speed (b) of the concentration of the solid phase of the slurry. 
The data from Table 2 and the graphs in Figure 3 show that the flow parameters of the slurry are highly dependent on the solids concentration. So, with a 1.4 times increase in mass concentration the pressure loss increases by 13 times, the diameter of the pipe decreases 10 times, and the average speed increases by almost 60 times, the volumetric flow of the slurry decreases 1.6 times. Such ratios are also observed for other values of the Reynolds number. The relationship between head loss and shear stress is expressed by the following relationship:

$$
i_{h}=\frac{4 \tau_{w}}{\rho_{h} g D_{\text {pipe }}}
$$

where: $\tau_{w}$ - shear stress on pipe wall:

$$
\tau_{w}=\frac{i_{h} \rho_{h} g D_{\text {pipe }}}{4}
$$

The calculated shear stress values are shown in Table 3 .

\section{Table 3.}

The calculated values of the shear stress on the pipe wall when the mass concentration

\begin{tabular}{|c|c|c|c|c|c|c|}
\hline $\begin{array}{c}\text { Mass } \\
\text { concentration } \\
c_{p} \\
\end{array}$ & $\begin{array}{c}\text { Volume } \\
\text { concentration } \\
c_{p} \\
\end{array}$ & $\begin{array}{c}\text { Solid to liquid } \\
\text { ratio } \\
\mathrm{S} / L \\
\end{array}$ & $\begin{array}{c}\text { Reynolds } \\
\text { Number } \\
\text { Re }\end{array}$ & $\begin{array}{c}\text { Pulp } \\
\text { density, } \\
\mathrm{kg} / \mathrm{m}^{3}\end{array}$ & $\begin{array}{c}\text { Hydraulic } \\
\text { slope, } \\
i_{h}, \mathbf{m} / \mathbf{m}\end{array}$ & $\begin{array}{l}\text { Shear } \\
\text { stress, } \\
\tau_{w}, \mathrm{~Pa}\end{array}$ \\
\hline 0.536 & 0.3 & $1 / 0.864$ & \multirow{5}{*}{3500} & 1510 & 0.002 & 20.21 \\
\hline 0.592 & 0.35 & $1 / 0.687$ & & 1592 & 0.004 & 23.4 \\
\hline 0.643 & 0.4 & $1 / 0.555$ & & 1680 & 0.010 & 34.7 \\
\hline 0.688 & 0.45 & $1 / 0.453$ & & 1765 & 0.021 & 43.5 \\
\hline 0.73 & 0.5 & $1 / 0.37$ & & 1850 & 0.052 & 64.8 \\
\hline 0.536 & 0.3 & $1 / 0.864$ & \multirow{5}{*}{4000} & 1510 & 0.002 & 17.7 \\
\hline 0.592 & 0.35 & $1 / 0.687$ & & 1592 & 0.005 & 25.7 \\
\hline 0.643 & 0.4 & $1 / 0.555$ & & 1680 & 0.011 & 33.4 \\
\hline 0.688 & 0.45 & $1 / 0.453$ & & 1765 & 0.025 & 45.3 \\
\hline 0.73 & 0.5 & $1 / 0.37$ & & 1850 & 0.064 & 70 \\
\hline 0.536 & 0.3 & $1 / 0.864$ & \multirow{5}{*}{4500} & 1510 & 0.002 & 15.7 \\
\hline 0.592 & 0.35 & $1 / 0.687$ & & 1592 & 0.005 & 22.7 \\
\hline 0.643 & 0.4 & $1 / 0.555$ & & 1680 & 0.012 & 32.4 \\
\hline 0.688 & 0.45 & $1 / 0.453$ & & 1765 & 0.029 & 46.8 \\
\hline 0.73 & 0.5 & $1 / 0.37$ & & 1850 & 0.078 & 75.7 \\
\hline 0.536 & 0.3 & $1 / 0.864$ & \multirow{5}{*}{5000} & 1510 & 0.002 & 14.1 \\
\hline 0.592 & 0.35 & $1 / 0.687$ & & 1592 & 0.006 & 24.6 \\
\hline 0.643 & 0.4 & $1 / 0.555$ & & 1680 & 0.014 & 34.0 \\
\hline 0.688 & 0.45 & $1 / 0.453$ & & 1765 & 0.033 & 47.8 \\
\hline 0.73 & 0.5 & $1 / 0.37$ & & 1850 & 0.097 & 86.3 \\
\hline
\end{tabular}
and the Reynolds number change

Figure 4a shows graphs of the change in shear stress on the pipe wall versus the Reynolds number. From the graphs it can be seen that in the mass concentration range from 0.536 to 0.665 , the shear stress is directly proportional to the change in the Reynolds number. When the mass concentration is $c_{p}=0.665\left(S: L=1: 0.503\right.$; volume concentration is $\left.c_{v}=0.42\right)$, the shear stress for all the Reynolds numbers is the same and equals $40 \mathrm{~Pa}$. In this range of concentration changes, the values of shear stress depend little on the Reynolds number. The point of intersection of the shear stress curves determines the effective concentration of the solid phase 
with equal values of resistances on the wall of the pipeline. When the effective concentration is reached, the pressure loss during pumping the pulp will differ slightly from each other with a certain increase in the Reynolds number, Figure $4 \mathrm{~b}$.

a)

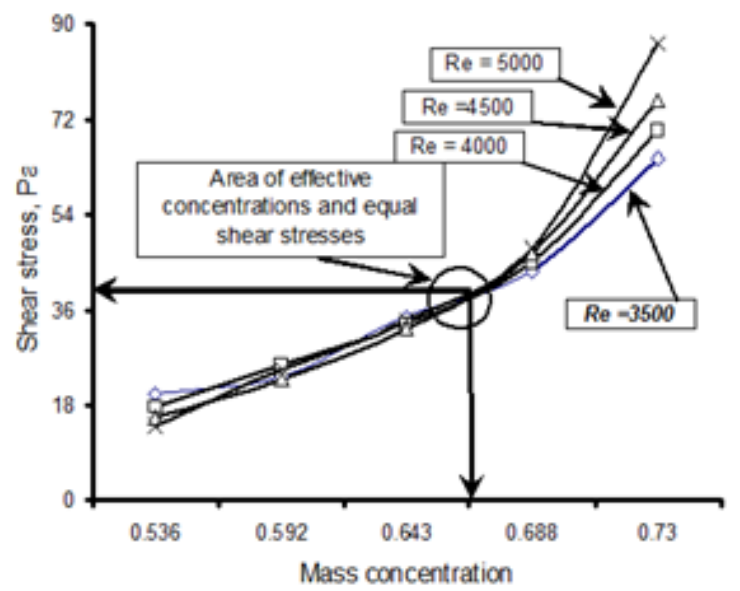

b)

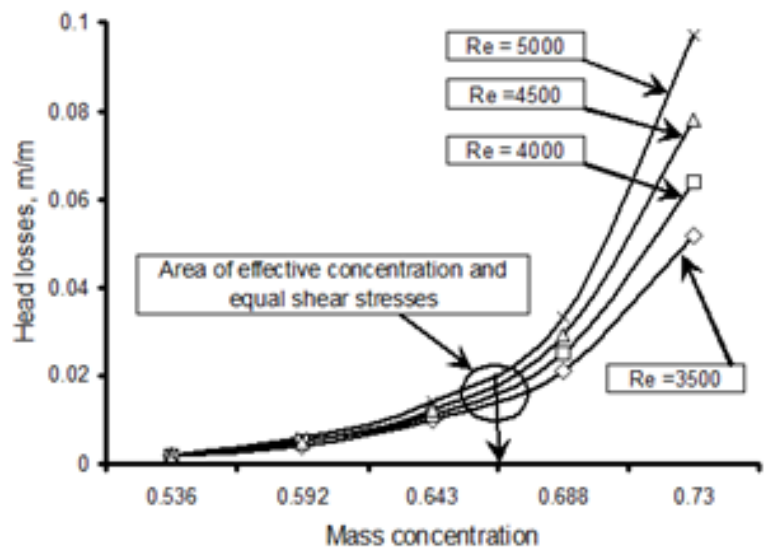

Figure 4. The dependence of shear stress (a) and pressure loss (b) on the mass concentration of the slurry when changing the Reynolds number.

\section{The results of viscometric studies}

Experiments on a rotational viscometer VT-350 were performed to study the rheological characteristics of the tailings hydromixes. Slurries with a solid mass content of 60,65 , and $70 \%$ were compiled for experiments. Rheograms of shear stress $\left(\tau_{w}\right)$ versus shear rate were obtained, Figure 5a.
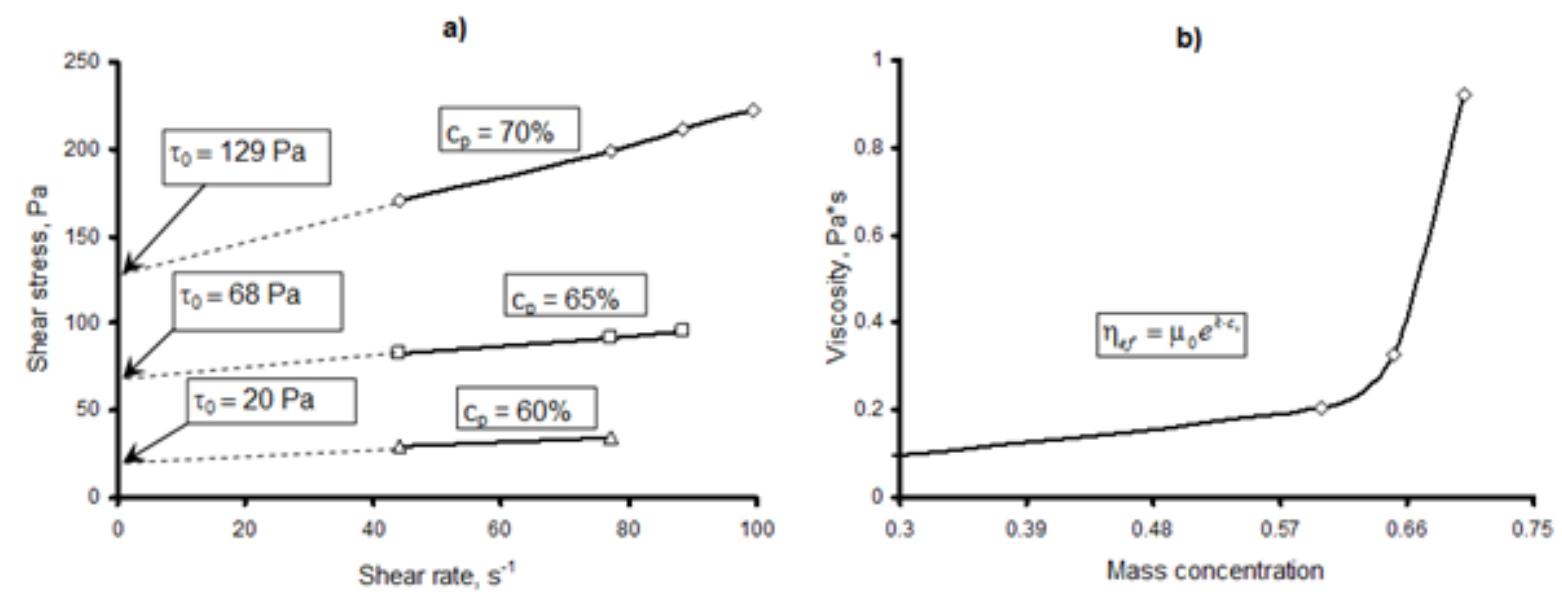

Figure 5. Rheological curves (a) and dynamic viscosity coefficient based on mass concentration of slurry (b). 
The graphs show that the maximum shear stresses occur in the slurry with a maximum concentration of $c_{p}=70 \%$. Maximum stresses were observed at the initial moment of the sensor rotation, which can be explained by the formation of a solid spatial structure in the slurry volume. The structural connections are destroyed with an increase in the rotation frequency, and the shear stresses decrease. At a rotation frequency of $20 \mathrm{~s}^{-1}$, shear stresses take the smallest value $(169.7 \mathrm{~Pa})$ and, a proportional increase in shear stresses occurs with further increase in the rotation speed. The point of intersection of the rheogram extension with the stress axis gives the values of the yield shear stress $-\tau_{0}$. For slurry with a $70 \%$ concentration the yield shear stress is approximately $129 \mathrm{~Pa}$, for $65 \%$ concentration $-\tau_{0}=68 \mathrm{~Pa}$; for $60 \%$ concentration $\tau_{0}=20 \mathrm{~Pa}$. The tangent of the rheological curves angle of inclination to the abscissa axis determines the value of the effective viscosity dynamic coefficient $-\eta_{e f}$. So for the mass concentration $c_{p}=70 \%-\eta_{e f}=0.923 \mathrm{~Pa} \cdot \mathrm{s} ; c_{p}=65 \%-\eta_{e f}=0.3258 \mathrm{~Pa} \cdot \mathrm{s} ; \mathrm{cf}=60 \%-\eta_{e f}=$ $0.2058 \mathrm{~Pa} \cdot \mathrm{s}$. These viscosity values make it possible to determine the nature of the change in viscosity as a function of concentration, Figure 5b. Curve in Figure $5 \mathrm{~b}$ can be described by a power function of the form:

$$
\eta_{e f}=\mu_{0} e^{k \cdot c_{v}}
$$

where:

$\mu_{0}$ - dynamic coefficient of viscosity of pure (circulating) water,

$\mathrm{Pa} \cdot \mathrm{s} ; k$ - experimental coefficient depending on the properties of the slurry (structural number $\mathrm{n}$ ), $c_{v}$ - volume concentration of slurry.

It is possible to determine the functional dependence of the yield shear stress $\tau_{0}$, which is included in the Bingham formula, from the rheological curves shown in Figure 5a. The curve view is shown in Figure 6.

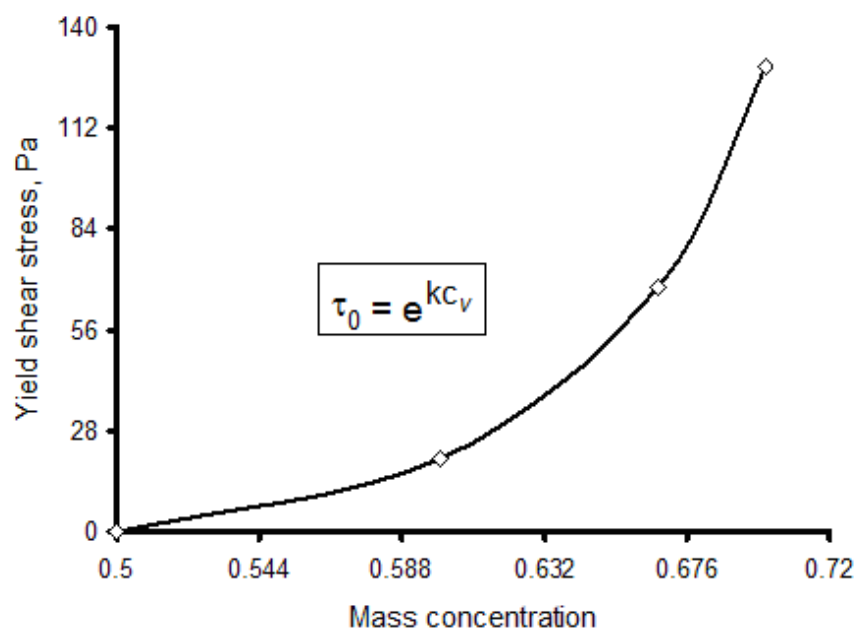

Figure 6. Dependence of the yield shear stress on the mass concentration of slurry. 
Thus, all the parameters included in the formula of Bingham-Shvedov were determined experimentally on a VT-350 viscometer. Using the obtained dependences, it is possible to calculate the magnitude of the pressure loss in a given range of changes in the slurry concentration. Taking into account the results of preliminary calculations and graphs shown in Figure 5 and Figure 6, it is possible to determine the value of the maximum possible concentration of the solid phase in slurry. The results obtained must be compared with the experimental data on the pipes.

\section{Experimental data on head loss}

Experimental work to determine the head loss during hydrotransportation of the goldbearing ore tailings from the processing was carried out on a laboratory pipe loop, the scheme and the general view of which are shown in Figure 7.

The experimental data, Table 5, show that the head loss increases with increasing flow rate and with increasing mass concentration of the slurry. The maximum head loss of $0.524 \mathrm{~m}$ water/m was observed in experiments with a slurry concentration of $65 \%$, and with the smallest concentration of slurry of $55 \%-0.186 \mathrm{~m}$ water $/ \mathrm{m}$.
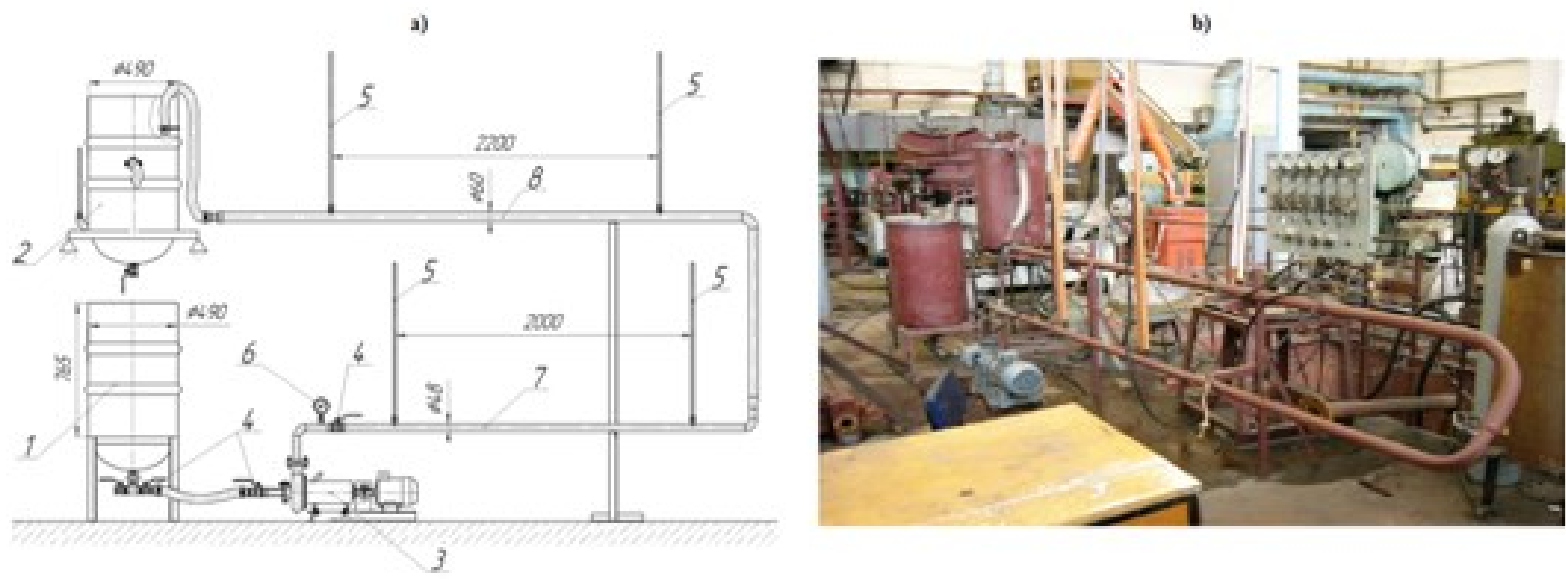

Figure 7. The scheme of the experimental laboratory stand: 1 - tank $2001 ; 2$ - measuring tank; 3 - centrifugal pump; 4 - ball valve; 5 - piezometer; 6 - manometer; 7 - pipe $\mathrm{D}=40 \mathrm{~mm}$; $8-$ pipe $\mathrm{D}=50 \mathrm{~mm}$.

Figure 8 shows the graphical dependences of head loss on the flow velocity, based on experimental data. 


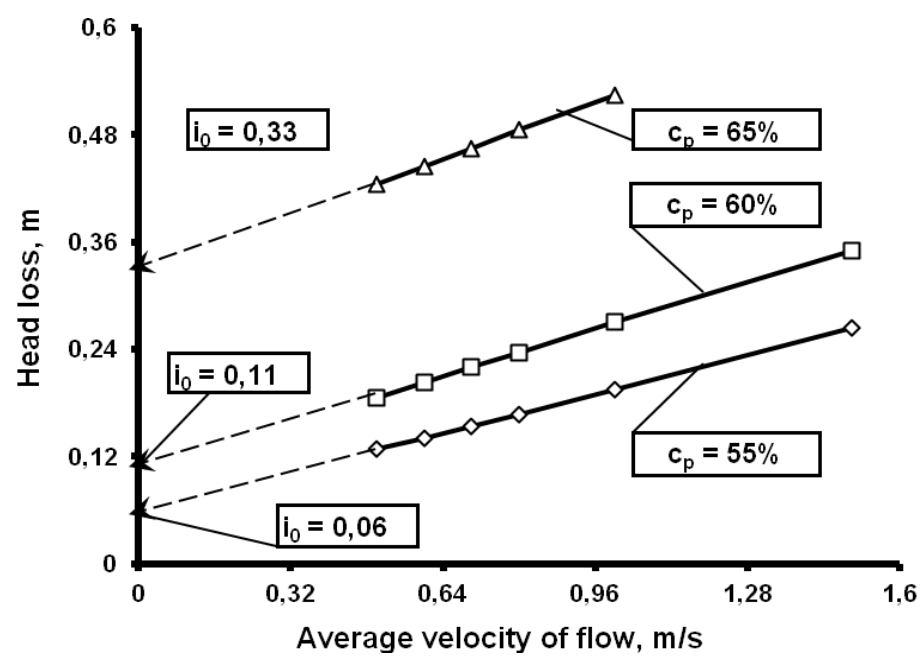

Figure 8. Head loss from average speed slurry flow when changing the mass concentration of slurry according to experiments $\left(i_{0}\right.$ - yield hydraulic slope).

The flow curves are expressed by a flow velocity linear function. Each slurry is characterized by a certain flow curve angle of inclination, indicating a change in the dynamic viscosity coefficient. The linear nature of the curves corresponds to the laminar flow regime. The continuation of the flow curves to the intersection with the axis of ordinates (head) indicates the presence of an initial hydraulic slope $-i_{0}$. The flow curves in Figure 8 can be represented by the following linear dependence:

$$
i_{h}=i_{0}+k v_{m}
$$

where:

$i_{h}$ - head loss, $\mathrm{mWC} / \mathrm{m}$,

$i_{0}$ - initial (static) slope,

$k$ - coefficient of proportionality,

$v_{m}$-average velocity of slurry, $\mathrm{m} / \mathrm{s}$.

The calculated values of the coefficient $\mathrm{k}$ and the corresponding Reynolds numbers are shown in Table 4.

Table 4.

The calculated values of the coefficient $k$ and the Reynolds number Re

\begin{tabular}{|l|l|l|l|l|l|}
\hline $\begin{array}{c}\text { Concentration, } \\
\boldsymbol{c}_{\boldsymbol{p}}\end{array}$ & \multicolumn{1}{|c|}{$\begin{array}{c}\text { Slope, } \\
\boldsymbol{i}_{\boldsymbol{h}}\end{array}$} & $\begin{array}{c}\text { Initial slope } \\
\boldsymbol{i}_{\mathbf{0}} \text { (Fig.7) }\end{array}$ & $\begin{array}{c}\text { Coefficient, } \\
\boldsymbol{k}\end{array}$ & $\begin{array}{c}\text { Viscosity, } \\
\boldsymbol{\eta}_{\boldsymbol{e f}}\end{array}$ & $\begin{array}{c}\text { Reynolds } \\
\text { number }\end{array}$ \\
\hline 0,65 & 0,524 & 0,33 & 0,194 & 0,3258 & 260 \\
\hline 0,6 & 0,27 & 0,11 & 0,16 & 0,2058 & 390 \\
\hline 0,55 & 0,195 & 0,06 & 0,135 & 0,144 & 520 \\
\hline
\end{tabular}

Note: the values of the dynamic viscosity coefficient $\eta_{e f}$ are taken from the graph in Figure 8 , the pipe diameter is $D_{\text {pipe }}=0.05 \mathrm{~m}$, the average flow velocity is $v_{h}=1 \mathrm{~m} / \mathrm{s}$. 
Graphic dependences of the coefficient $\mathrm{k}$ and the initial hydraulic slope $\mathrm{i}_{0}$ on the slurry mass concentration according to Table 5 are shown in Figure 8, and the dependence of the Reynolds number is shown in Figure 9.

Coefficient $k$ varies linearly with the concentration of the slurry and can be calculated at all possible concentrations using the formula:

$$
k=0.59 c_{p}-0.189
$$

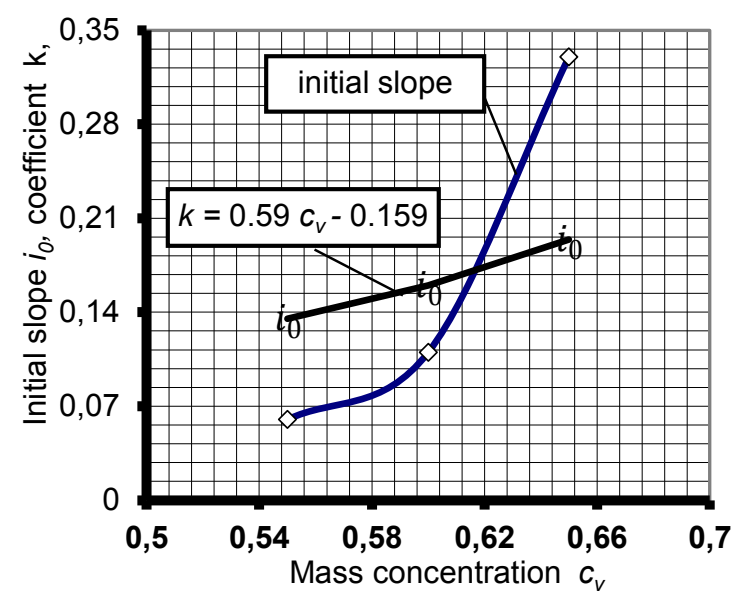

Figure 9. Graphic dependences of the coefficient $\mathrm{k}$ and the initial hydraulic slope $i_{0}$ on the mass concentration of the slurry.

It is possible to calculate the value of the pressure loss with the known value of the coefficient $k$ using the formula:

$$
i_{h}=k \cdot v_{h}+i_{0}=v_{h}\left(0.59 \cdot c_{p}-0.189\right)+i_{0}
$$

\section{Comparison of results obtained on the VT-350 viscometer and experiments in pipe}

The experiments results confirm that the slurry of gold-bearing ore tailings from the Verninskaya processing factory at mass concentrations of 55\% and above exhibit the properties of viscoplastic fluids described by the Bingham-Shvedov equation. The rheological curves constructed from the results of viscometric studies (shown in Figure 5) coincide in shape with the curves for head loss based on the results of experiments in pipes (Figure 7). The yield shear stress on the rheological curves corresponds to the values of the initial head loss on the curves of flow. The shear stress in the rheological curves corresponds to the values of head loss in pipe. It is sufficient to recalculate the values of shear stresses by the value of the head losses in the pipe to determine the correspondence of the rheological characteristics to the experimental data on the pipes. We'll have for mass concentration $c_{p}=0.65 ; \tau_{w}=\tau_{0}+\eta_{t f} \dot{\gamma}$. Insert the 
data $\tau_{0}=68 \mathrm{~Pa}$ (Figure 5a), $\eta_{e f}=0.3258 \mathrm{~Pa} \cdot \mathrm{s}$ (Figure 5b); $\dot{\gamma}=\frac{8 v_{h}}{D_{\text {pipe }}}=\frac{8 \cdot 1,0}{0.05}=160 \mathrm{~s}^{-1}$. The shear stress on the wall of the pipeline will be equal to $\tau_{w}=68+0.3258 \cdot 160=120 \mathrm{~Pa}$. Head loss in pipe will be equal:

$$
i_{h}=\frac{4 \cdot \tau}{\rho_{h} \cdot g \cdot D_{\text {pipe }}}=\frac{4 \cdot 120}{1695 \cdot 9.81 \cdot 0.05}=0.577 \mathrm{mWc} / \mathrm{m}
$$

The actual value of the hydraulic slope measured during the experiments on the pipeline is $i_{a k t}=0.524 \mathrm{mWc} / \mathrm{m}$ (Table 5). Relative error in calculation of the results:

$$
\varepsilon=\frac{i_{h}-i_{a k t}}{i_{\text {akt }}} 100 \%=\frac{0.577-0.524}{0.524} 100 \%=10.1 \%
$$

\section{Conclusions}

1. Slurry of gold-bearing ore tailings from the Verninskoye deposit with mass concentrations greater than $55 \%$ is a viscoplastic fluid.

2. Viscometric studies on a rotational viscometer allowed us to establish the main rheological characteristics of the slurries, i.e. shear stress $-\tau_{w}$ and the dynamic viscosity coefficient $-\eta_{e f}$. Over the entire range of concentrations from 55 to $65 \%$, the flow of slurries is described by the Bingham rheological equation.

3. The main rheological characteristics that determine the energy intensity of hydraulic transport are the yield shear stress $\tau_{0}$ and the effective viscosity $\eta_{e f}$, which are constant values for the slurry with a given concentration, and the shear rate $\dot{\gamma}$, depending on the average flow velocity and diameter of the pipeline in the laminar flow region.

4. Experimental studies of hydraulic transport, performed on a laboratory installation with a pipeline diameter $50 \mathrm{~mm}$ confirmed the results obtained on a rotational viscometer.

5. Curved flows are inclined straight lines that cut off the segments on the axis of the head, which determine the initial hydraulic slope corresponding to the yield shear stress on the rheological curves.

6. Recalculation of pressure characteristics to shear stresses showed that the average deviation of the calculated and actual results does not exceed $10 \%$. This fact indirectly confirms the adequacy of the results obtained on a viscometer and on a laboratory hydrotransport setup.

The obtained results can improve the efficiency of the tailings transportation process. That allows a complete modernization of the technological process of pumping tailings and the development of new design solutions by thickening the slurry of gold-bearing ore tailings. There are some limitations of using the research results: mass concentrations of gold-bearing ore tailings slurry should be above 55\%. 


\section{References}

1. Aleksandrov, V.I., Avksentyev, S.Yu., Gorelkin, I.M. (2012). Obogashchenie Rud. Mineral Processing, 3, 39-42.

2. Aleksandrov, V.I., Vasylieva, M.A. (2015). Reports of the XXIII Int. Sci. Symp., Miner's week, 452-460.

3. Alexandrov, V.I. (2000). Metody snizhenia energozatrat pri gidravlichtskom transportirovanii smesei vysokoi koncentracii. Saint-Petersburg, SPGMI (TU), 117.

4. Alexandrov, V., Ivanov, S., Asatur, K., Demijanov, S. (2015). The rheological properties of high concentration slurry at pipeline transportation on example of copper-nickel ore tailings. $14^{\text {th }}$ International Conference on Transport and Sedimentation of Solid Particles, 23-27 June, Saint Petersburg, Russia, 23-32.

5. Avksentiev, S.Yu., Serzhan, S.L., Trufanova, I.S. (2018). GIAB S11, 3-14, DOI: 10.25018/0236-1493-2018-4-11-3-14.

6. Darcy, H. (1857). Malet-Bachelier.

7. Debray, F., Franc, J.P., Maitre T., Reynaud. S. (2001). Mec. Ind. 2, 443-454.

8. Heywood, N., Richardson, J. (1978). Proc. Hydrotransport, 5 C1, 146-152.

9. Kumar, U., Singh, S.N., Seshadri, V. (2015). Int. J. of Engineering and Technical Research (IJETR), 3(4), 394-397.

10. Paterson, A.J.C. (2004). High density slurry and paste tailings, transport systems. International Platinum Conference 'Platinum Adding Value'. The South African Institute of Mining and Metallurgy, 45-56. 